\title{
Assessing the Financial and Social Costs of Public Transport in Differing Operating Environments and with Endogenous Demand
}

\author{
XUCHENG LI ${ }^{1}$, JOHN PRESTON \\ Transportation Research Group, Faculty of Engineering and the Environment, \\ University of Southampton, Southampton, UK
}

Faculty of Engineering and the Environment, University of Southampton, Boldrewood, Southampton, UK, SO16 7QF.

${ }^{1}$ Corresponding author. Email: X.C.Li@soton.ac.uk 


\section{Assessing the Financial and Social Costs of Public Transport in Differing Operating Environments and with Endogenous Demand}

This paper uses a previously developed spreadsheet cost model which simulates public transport modes operated on a $12 \mathrm{~km}$ route to analyse the total costs of different passenger demand levels. The previous cost model was a very powerful tool to estimate the social and operator costs for different public transport technologies. However, as the model is strategic, some basic assumptions were made which are relaxed in this paper. Firstly, the speed-flow equation in the original spreadsheet model assumes that speed decreases according to the ratio of the current frequency and the lane capacity which is based on the safety headway without taking into account passenger boardings. However, this may vary in different operating environments. Therefore, the speed-flow equation is improved by moving from a linear equation to a piecewise equation that considers the features of different operating environments. Secondly, the model assumes that supply is sufficient to meet demand. However, when the level of demand is high for the lower capacity public transport technologies, passengers may find the incoming vehicle full and therefore they have to wait more than one service interval. This paper applies queuing theory to investigate the probability of having to wait longer than the expected service headways which will affect the average passenger waiting time. The extra waiting time for each passenger is calculated and applied in the spreadsheet cost model. Thirdly, the original model assumed demand was externally fixed (exogenous). To evaluate the differences after applying these equations, endogenous demand rather than exogenous demand will be investigated by using the elasticities for passenger waiting time and journey time.

Keywords: transport planning; cost modelling; passenger demand/supply

Word count: 6303

\section{Introduction}

Public transport is one of the most important means of daily travel for purposes such as commuting, shopping and education especially in large cities where the costs of travelling by private vehicles are high due to the lack of space. Passenger journeys on 
local bus services in the UK in 2010 has increased by approximately 13\% since 2004/05 (up 29\% in London and 2.8\% outside London), the passenger journeys of light rail and tram systems have increased by $28.7 \%$ over the same period while the passenger journeys by national rail have doubled since privatisation (1994/1995) (Department for Transport, 2012). The benefits of developing public transport are being recognised by governments all around the world. Many new intermediate public transport modes have been developed to meet various passenger requirements. For low levels of demand, the ULTra (Urban Light Transit) Personal Rapid Transit (PRT) system in London Heathrow Airport works as a feeder service for people between the business car park and the terminals and takes only 5-6 minutes to travel along approximately 1.2 miles (ULTraGlobalPRT, 2011). For medium levels of demand, the $450 \mathrm{~m}$ outbound and 750 $m$ inbound Guided Bus system in Leeds ensures punctuality and reliability and increases the attractiveness of bus services by providing a segregated busway, and this reduces journey time by $33 \%$ and increase patronage by $40 \%$ (Currie and Wallis, 2008). For higher levels of demand, the light rail system operating in Greater Manchester (Metrolink) provides more frequent services as well as cheaper fares than the previous heavy rail system, while maintaining competitiveness in terms of operating speed and punctuality, and because of these characteristics the Metrolink successfully achieved its ridership projections while most new urban rail systems failed to reach their initial targets (Knowles, 2007). A cost-effective technology, Bus Rapid Transit (BRT), is operated in a wide number of countries. Buses run on a segregated busway with dedicated stops which results in a maximum running speed of up to $100 \mathrm{kph}$ and no congestions in peak hours. Demand has reached 15,000 per hour after only 5 years operation of the BRT system in Brisbane while the long term maximum peak hour demand was forecasted to be 10,000 per hour (Currie, 2006). The Straddle Bus is a new 
invention launched at the 13th Beijing International High-tech Expo in 2010 which operates above the traffic with girder-like legs straddling the road and leaves room for general traffic with multiply car-unit similar to light rail transit. It is believed to be able to solve the traffic congestion in metropolises such as Beijing and London by having fewer interactions with other forms of transport, while carrying many more people than conventional buses with lower construction cost than new underground line or rapid transit lane (McDermon, 2010).

These new public transport modes would have different feasibility at distinct demand levels, and the costs would also vary. Therefore, comparing their costs in the same situation is an essential issue. The cost of public transport technologies consists of not only of the costs faced by operators (which may be expected to be passed on to user in terms of fares) but also the costs borne by society in general (Jakob et al. 2006) which is the total social cost.

Previous studies have been carried out in the TEST (Tools for Evaluating Strategically Integrated Public Transport) project by Brand and Preston (2001, 2002a, 2002b, 2003a, 2003b, 2006) and Li and Preston (2014). Based on the pioneering study of Meyer, Kain and Wohl (1965) on the operator costs for different transport modes (auto, bus and rail) in different population density areas, their work proposed a spreadsheet cost model in Microsoft Excel and an integrated simulation model by using transport analysis software VIPS (now part of the wider VISUM model) (for public transport) and CONTRAM (for private transport). The spreadsheet cost model compared up to 15 conventional, new intermediate and innovative forms of public transport on the basis of the average and marginal social costs (in pence per passenger kilometre) which include user costs and external costs rather than just the costs for the operator on a $12 \mathrm{~km}$ single route corridor. The speed-flow equation used in the 
spreadsheet model is a linear equation rather than a power law or piecewise linear function (Small, 1992). The waiting time for public transport passengers in the user cost section considers service frequency only. However, passengers may experience additional delay when they find the incoming vehicle is full at high levels of demand. The demand level increments in the model are all externally fixed which means the results are all based on fixed demand predictions. In reality, passenger demand levels are endogenous, not exogenous, and are affected by the performance of the public transport services such as the service interval and journey time. The actual average costs could be substantially different from those assuming fixed demand because actual passenger demand will vary due to the quality of service.

Therefore, the objectives of this paper are:

(1) To improve the speed-flow equation of the spreadsheet cost model by using a piecewise function and adding the facility capacity factor for the advantages in different operating environments.

(2) To take the probability of passengers having to wait longer than service headways into account for the average passenger waiting time calculation.

(3) To evaluate the results of applying the revised speed-flow and waiting time functions by investigating the endogenous relationship between demand and supply and then comparing the average social costs of single-decker bus services in different operating environments.

The organisation of this paper is as follows. Section 2 demonstrates the application of the new speed-flow equation in the spreadsheet model by considering the impact of other vehicles in the traffic flow. Section 3 presents the equations for calculating the passenger waiting time with queuing theory. Section 4 gives the analysis 
of the impact of endogenous demand and section 5 draws some conclusions and outlines potential future work.

\section{The Spreadsheet Model}

\subsection{Introduction of the Spreadsheet Model}

This spreadsheet cost model developed in the TEST project by Brand and Preston (2006) was based on the study of social costs by Jansson (1984) who developed the concept of social costs as the sum of total producer costs and total user costs and the work on operator costs by Meyer, Kain and Wohl (1965) who developed equations for total operator and other non-structural costs of rail and bus transit.

The TEST project developed total social costs as the sum of total operator costs, total user costs and total external costs:

$$
T S C=T O C+T U C+T E C
$$

Equation 1

where TSC is the total social cost, TOC is the total operator cost, TUC is the total user cost and TEC is the total external cost.

The total operator cost covers all investment by operators of the public transport service which contains two sectors: capital cost and maintenance cost. The capital cost of the public transport technologies consists of infrastructure and vehicle costs which are broke down into amortised cost of their economic lives by assuming an annual interest rate of $3.5 \%$, and the annual maintenance costs are made up of time-related, distance-related, route maintenance and vehicle-related costs for each forms of public transport. The total user cost is highly related to the speed of the public transport services. It includes the time passengers spend on walking to the station, waiting for the bus and travelling on the bus and converts into costs by using the passengers' value of time. The total external cost accounts for any external impacts of using the public 
transport technology such as air pollution, noise pollution, climate change and accidents. Details of the default value used in the spreadsheet model can be found in Brand \& Preston (2002b) and Li \& Preston (2014).

There are a number of assumptions made in the TEST model. The TEST model is based on the core operating day time services (07:00 to 18:00). Three time periods have been identified in this model: morning peak, evening peak and off peak period. The lengths of these time sectors are assumed to be 2 hours for each peak time and 7 hours for the off peak and 11 hours of steady operating period in total. The daily passenger demands are split into these time period which is $22.5 \%$ for each peak period and $55 \%$ for the off peak.

\subsection{Revised Speed-Flow Equation}

The spreadsheet model calculations are based on the input of estimated demand and parameters of the public transport technologies and are either set by the user or use the default values. With initial input data, the model can then obtain the intermediate outputs such as required service frequency and average operational speed which are the two key factors to calculate the costs. The required service frequency function is defined as:

$$
F=\frac{\alpha \times P A X}{V e h C a p \times M a x L F}
$$

where $\mathrm{F}$ is the service frequency $(\mathrm{veh} / \mathrm{h}), \alpha$ is the factor to allow for seasonal fluctuations for which the default value is 1.1 and can be modified by the user, PAX is the demand for the time period in passengers number per hour, VehCap is the vehicle capacity including seating and standing spaces and MaxLF is the maximum relative load factor at which level a new vehicle is required which is set to $50 \%$ as default. The 
required service frequency is associated with the average operational speed $V^{A L L}\left(\mathrm{~km} \mathrm{~h}^{-}\right.$ ${ }^{1}$ ) which is calculated with the speed-flow equation of:

$$
V^{A L L}=V^{N o C a p}\left(1-\frac{F}{C}\right)
$$

Equation 3

In this equation, $\mathrm{V}^{\text {NoCap }}$ is the vehicle operational speed $\left(\mathrm{km} \mathrm{h}^{-1}\right)$ calculated by using the default value (or user defined) of acceleration, maximum speed, station spacing, stopping time and passenger boarding/alighting time without considering the capacity of the infrastructure, and the variable $\mathrm{C}$ is the infrastructure capacity (veh/h) which is the maximum possible vehicle numbers per lane (for road-based systems) or per track (for rail-based systems). With the restraint of the infrastructure capacity, the average operational speed can then reflect the traffic situation as the system becomes congested due to rises in passenger demand. The infrastructure capacity can be defined by users for the technologies which allow overtaking or calculated by the equations as follows for technologies where overtaking is not possible.

$$
\begin{array}{cc}
C=\frac{3600}{H} & \text { Equation } 4 \\
H=T^{V e h}+\sqrt{\frac{2 L^{V e h}}{A}}+\frac{L^{V e h}}{V^{M a x}}+\frac{V^{M a x}}{2 A} & \text { Equation } 5
\end{array}
$$

where $\mathrm{H}$ is the safety headways in seconds to calculate the minimum possible service interval without any passenger boarding, $\mathrm{T}^{\mathrm{Veh}}$ is the vehicle stopping time in seconds which includes opening/closing doors and changing shifts for drivers, $\mathrm{L}^{\mathrm{Veh}}$ is the length of the vehicle in meters, $\mathrm{V}^{\mathrm{Max}}$ is the maximum possible running speed $\left(\mathrm{m} \mathrm{s}^{-1}\right)$ and $\mathrm{A}$ is the acceleration and deceleration of the vehicle $\left(\mathrm{m} \mathrm{s}^{-2}\right)$.

The speed-flow equation in the spreadsheet model is a linear function (Equation 3). This is because the spreadsheet model assumed the public transport service is on a 
segregated $12 \mathrm{~km}$ route and the level of public transport traffic is fixed. However, the advantages of having a segregated road for the forms of public transport such as guided bus and rail-based public transport modes cannot be clearly shown in the cost model. If the service frequency requirement of the public transport service increases which means the passenger demand on the route is increased, the probability increases that not only the public transport vehicles themselves but also other traffic will delay the operating speed of the public transport services, either by causing congestion at the junctions or by blocking access in to or out of the stops.

The speed of the traffic flow can be estimated based on the number of the vehicles entering the route and the capacity of the roadway. As the travel time is highly related to the travel speed, a simple power law function can be used to demonstrate the relationship of traffic volume and travel time, and the power law function is:

$$
1 / S=T_{0}+T_{1}\left(V / V_{K}\right)^{k} \quad \text { Equation } 6
$$

where $\mathrm{T}_{0}, \mathrm{~T}_{1}$, and $\mathrm{k}$ are parameters, $\mathrm{V}$ is the traffic volume, $S$ is the travel speed and $\mathrm{V}_{\mathrm{K}}$ is the capacity. This power law function is postulated for single links in a network by the U.S Bureau of Public Roads with $\mathrm{k}=4$ and $\mathrm{T}_{0} / \mathrm{T}_{1},=0.15$ and widely used in many economic models (Small, 1992). Small (1992) also derived another function to express the travel time over a peak period, which is a piecewise linear function:

$$
1 / S=\left\{\begin{array}{ll}
T_{0} & V \leq V_{K} \\
T_{0}+T_{1}\left(V / V_{K}-1\right) & V>V_{K}
\end{array} \quad \text { Equation } 7\right.
$$

Parameters are estimated for both the power law function and the piecewise linear function and average maximum delay against daily vehicles are plotted, and the piecewise linear function fits slightly better (Small, 1992, page 71-72). 
However, these functions are for calculating the speed and travel time in mixed traffic flow, given the capacity of the roadway. Many innovative forms of public transport tend to operate on either transit lanes (guided bus, light rail etc.) or gradeseparated rights-of-way (Personal Rapid Transit, underground etc.) to avoid the delay caused by other vehicles. Facility capacity will vary in different operating environments of the public transport service. For example, conventional bus service may experience congestion and the operating speed will start to decrease at a lower level of passenger demand than those bus services operating on segregated busway such as the guided bus and Bus Rapid Transit. The method of determining the lane capacity of a public transport technology in the TEST project is to consider the minimum headway without any passenger boarding. Therefore a factor should be added to account for the differences between different operating environments.

The impacts of operating environment on capacity have been investigated and reported in Transit Capacity and Quality of Service Manual (Kittelson \& Associates, Inc., et al, 2013). There are four types of operating environments which are discussed in that manual, which are: mixed traffic, semi-exclusive, exclusive and grade separated. Mixed traffic operating environments mean the public transport mode has to shared lanes at all times with general traffic, such as the conventional bus service. Semiexclusive operating environments will have partially dedicated facilities for transit use, but are also available for other vehicles at certain times, such as buses on bus lane and light rail line with pedestrian access. Exclusive operating environments are defined as the facilities are dedicated for transit use at all times, but there may be some external traffic interaction at controlled locations (for example, guided bus or Bus Rapid Transit). Grade separated operating environments have no at-grade crossings, and facilities are fully dedicated to the transit vehicles (for example, underground). Facility 
capacity as percentage of base condition for different operating environments has been illustrated in Transportation Research Board's Transit Capacity and Quality of Service Manual (see, Kittelson \& Associates, Inc., et al, 2013, page 3-34), as shown in Table 1Table 1.

Table 1 Facility capacity as $\%$ of base condition in different operating environments

\begin{tabular}{cccccc}
\hline $\begin{array}{c}\text { Transit } \\
\text { Type }\end{array}$ & $\begin{array}{c}\text { Mixed Traffic } \\
\text { (urban street) }\end{array}$ & $\begin{array}{c}\text { Semi-exclusive } \\
\text { (transit lane) }\end{array}$ & $\begin{array}{c}\text { Exclusive } \\
\text { (street median) }\end{array}$ & $\begin{array}{c}\text { Exclusive } \\
\text { (private right-of-way) }\end{array}$ & (busway or subway) \\
\hline Bus & $\mathbf{3 8 \%}$ & $\mathbf{5 2 \%}$ & $\mathbf{6 1 \%}$ & $\mathbf{5 7 \%}$ & $\mathbf{1 0 0 \%}$ \\
Rail & $\mathbf{4 1 \%}$ & $\mathbf{6 7 \%}$ & $\mathbf{1 0 0 \%}$ & $\mathbf{9 2 \%}$ & $\mathbf{1 0 0 \%}$ \\
\hline
\end{tabular}

*data adapted from Transit Capacity and Quality of Service Manual (Kittelson \& Associates, Inc., et al, 2013)

The facility capacity is defined as the maximum possible service frequency of the public transport services calculated either by critical bus stop capacity (for bus transit) or by safety headways (for rail-based transit). The base condition for conventional bus services assumes 30 s dwell time, no traffic signals, 10s clearance time and $60 \%$ dwell time variation. For rail-based technologies, the base condition assumes 3-aspect train signals, 45s dwell time and 20s operating margin (details can be found in Kittelson \& Associates, Inc., et al, 2013, Chapter 6 \& Chapter 8).

According to Table 1Table 1, facility capacity varies for different transit modes and different operating environments, and the advantages of having a segregated transit lane are shown. For example, the operating speed of the bus service in a mixed traffic environment may begin to decrease earlier than the service mode with dedicated transit lanes if we consider a piecewise speed-flow equation. This facility capacity in different operating environments can be applied in the spreadsheet cost model to represent the advantages in the operating speed and the passengers' waiting time costs of the public transport services with higher infrastructure costs. 
To take the piecewise speed-flow equation and the facility capacity in different operating environments into account for the spreadsheet model, the speed equation will be:

$$
1 / S=\left\{\begin{array}{ll}
T_{0} & F \leq C_{F}(=f C) \\
T_{0}+T_{1}\left(F / C_{F}-1\right) & F>C_{F}(=f C)
\end{array} \quad \text { Equation } 8\right.
$$

where $\mathrm{f}$ represents the capacity percentage as listed in Table 1Table 1 and $\mathrm{C}_{\mathrm{F}}$ is the critical facility capacity $(\mathrm{veh} / \mathrm{h})$ calculated by f times the safety headway capacity $\mathrm{C}$. Since the spreadsheet model calculations use the operating speed of the public transport service instead of the average travel time as intermediate variable, we have:

$$
V^{A L L}=\left\{\begin{array}{ll}
V_{0}^{\text {NoCap }} & F \leq C_{F} \\
\frac{V_{0}^{\text {NoCap }} V_{1}^{\text {NoCap }}}{V_{1}^{\text {NoCap }}+V_{0}^{\text {NoCap }}\left(F / C_{F}-1\right)} & F>C_{F}
\end{array} \quad \text { Equation } 9\right.
$$

This function is derived from the piecewise linear function for travel time and uses the original safety headway capacity in the TEST project multiplied by the capacity percentage in different operating environments. To demonstrate the difference, the relationships between speed and passenger demand of the single-decker bus in mixed traffic and the single-decker bus on a busway from the spreadsheet cost model are shown in Figure 1Figure 1 and Figure 2Figure 2.

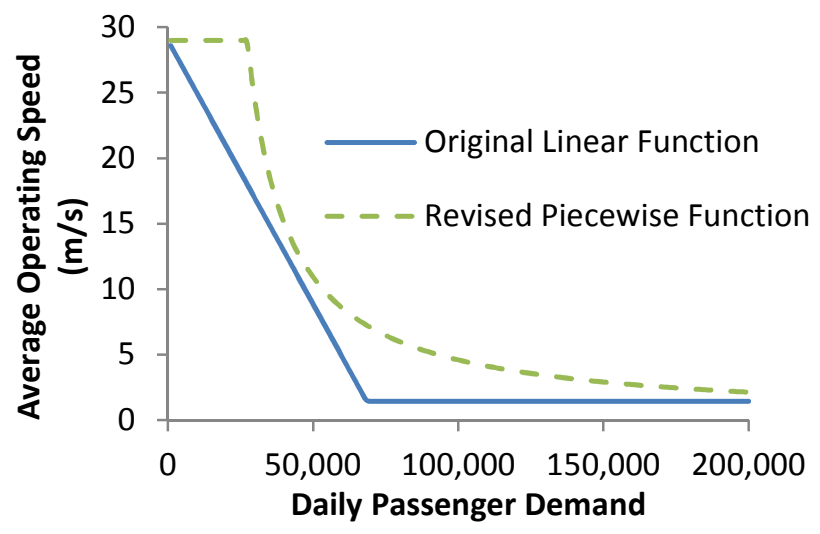

Figure 1 Average operating speed of single-decker bus in mixed traffic 


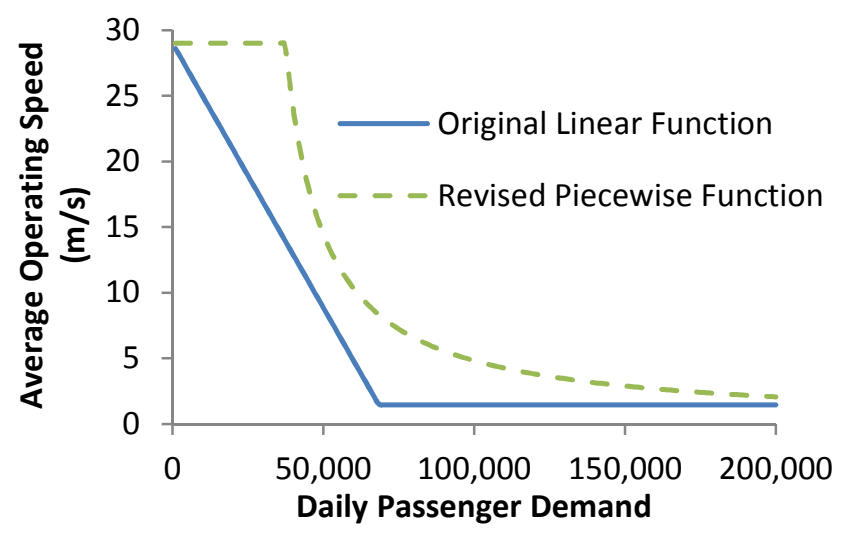

Figure 2 Average operating speed of single-decker bus on busway

From Figure 1Figure 1 and Figure 2Figure 2 we can see that, with the original linear function indicated as solid lines in the graphs, the average operating speed is the same for both public transport services, as their lane capacities (safety headways) are the same. The dashed line indicate the revised piecewise speed-flow function for average speed as shown in Equation 9 with the application of a facility capacity factor to account for the operating environment. For both bus services, there is no speed reduction until they reach the critical facility capacity, and then the travel time starts to increase linearly which means their average speeds decrease as a reciprocal function of flow, as shown in the graphs.

\subsection{Revised Passenger Waiting Time}

Passenger waiting time is one of the most important constituents of the total user cost for all public transport technologies. The calculations of the passenger waiting time in the original spreadsheet model assumed a classic formula for the mean waiting time, due to lack of information and the notably strategic nature of the model version, and the formula is:

$$
T^{\text {wait }}= \begin{cases}T^{\text {safe }} & \text { if } F<5 \\ \frac{H^{\text {freq }}}{2}+\frac{T^{\text {stop }}}{2} & \text { if } F \geq 5\end{cases}
$$


where $T^{\text {wait }}$ is the mean waiting time in seconds for each passenger, $T^{\text {safe }}$ is the fixed passenger waiting time in seconds when the service frequency is low, $H^{\text {freq }}$ is the service headways in seconds and $T^{S t o p}$ is the vehicle dwell time in seconds for each stop which is calculated by using fixed boarding time boarding time per passenger multiple by the passenger demand. This formula assumes all passengers at the stop have to wait half of the service headways plus half of the dwell time averagely before they start their journey when the service interval is greater than 12 minutes. Passengers will time their journey for a specific departure when the service interval is long (at a threshold of 12 - 15 minutes) (Balcombe et al., 2004), and a fixed safety waiting time $T^{\text {safe }}$ is used in this condition. Suppose all public transport passengers are evenly distributed and the service capacity can always meet the demand, this equation can correctly represent the passenger waiting time. However, passenger demand level varies at different stops for different time periods in reality. The distribution of passenger demand is cumulative and depends on the location of stops. The number of passenger loading at the stops close to the central business district could be much larger than other stops in peak time periods. There will be a probability that passengers at these stops find the incoming public transport vehicles full or with not enough space to take all waiting passengers, even though the overall capacity of the public transport service may still be higher than the total demand of the route. This situation may occur more often when the demand level is high because the vehicle capacity is fixed except for some rail-based technologies that are able to operate multiple car-units, and passengers who use lower vehicle capacity public transport services may have a higher possibility to wait longer than the expected service frequency for the busiest public transport stops.

The public transport service can be regarded as serving seats to passengers (customers) and each arrival vehicle means a bunch of customers are served. Therefore, 
passenger waiting time can be calculated by using queuing theory for the time spent by the queuing customers. In order to use the queuing theory for passenger waiting time calculation, we have to define the utilization rate of the system as:

$$
\rho=\frac{\lambda}{\mu}
$$

where $\rho$ stands for the utilization rate of the system, $\lambda$ is the passenger arrival rate and $\mu$ is the service frequency F. In the queueing theory calculation, the utilization rate is less than 1 . This is because when the incoming passenger number is higher than the facility capacity, the equilibrium queue length becomes unbounded and the waiting time of the late arrived passengers could be infinitely high. As this equation uses the same unit for the arrival passengers and the incoming public transport vehicles, we can assume the boarding passengers as a group by dividing a percentage of the vehicle capacity:

$$
\rho=\frac{Q / a C_{V e h}}{F}=\frac{Q}{a C_{V e h} F}
$$

where $Q$ is the average demand per hour, $C_{V e h}$ is the vehicle capacity and $a$ is the boarding/alighting rate to calculate the available spaces left for each incoming vehicle. To apply the queuing theory, specifications of the system have to be made for: the arrival process, the service mechanism and the queue discipline. The arrival process and service mechanism should be defined as either deterministic flow or some other random distribution for the way in which passengers and the public transport services arrive at the stop, respectively. The queue discipline defines the method to handle the incoming customers, which can be "first come first served" or "last come first served". Glaister (1981) demonstrates the method of calculating passenger queues of travel by any mode. By assuming a "first come first served" rule of service and a Poisson process for both 
the passenger arrival process and the bus service mechanism, Glaister (1981) gives the probability of having to wait longer than $W^{*}$ as:

$$
P=\rho \exp \left[-(\mu-\lambda) W^{*}\right] \quad \text { Equation } 13
$$

By substituting the service interval and Equation 12 into Equation 13 we have the probability of having to wait longer than one service headway as:

$$
P=\frac{Q}{a C_{V e h} F} \exp \left[-\frac{\left(F-Q / a C_{V e h}\right)}{F}\right] \quad \text { Equation } 14
$$

The parameter $\mathrm{W}^{*}$ has been substituted by $1 / \mathrm{F}$ which is the service interval, and the probability of having to wait for at least the third incoming vehicle can be calculated by simply replacing the $\mathrm{W}^{*}$ as $2 / \mathrm{F}$. To illustrate the result, the probability that the single-decker bus passengers in the peak period have to wait longer than the expected service headways at demand level of 60,000 per day is shown in Figure 3 Figure 3.

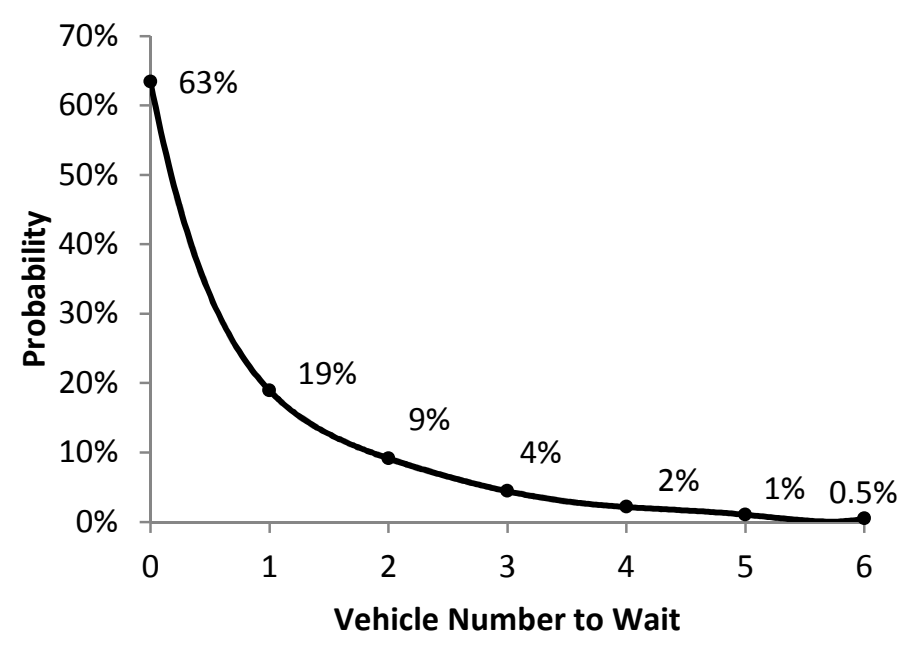

Figure 3 Probability of having to wait longer than service headways

Note that all parameters are using the default value in the spreadsheet cost model which can be modified by the user to incorporate different public transport technology characteristics. Although the public transport passengers along the corridor still have to 
be assumed evenly distributed, this equation considers the passenger arrival process using a Poisson distribution. It is suggested that $37 \%$ of the total passengers have to wait for more than one service interval of the bus service with a spare capacity of $30 \%$ of vehicle capacity. This spare capacity is calculated by using the load factor of the single-decker bus at this demand level in the spreadsheet model, which is calculated as the passenger demand divided by the service frequency times the vehicle capacity. This load factor was assumed to have an initial value of 0.5 in the spreadsheet model, and an extra public transport vehicle will be provided when the passenger demand equals to half of the supply spaces. The load factor will increase when the passenger demand level rises, which is because the supply has been limited by the capacity and the passenger demand may exceed the supply. To apply this probability into the spreadsheet cost model calculation of passenger waiting time, the average waiting time for each passenger at each stop will be:

$$
W T=\sum_{i=0}^{\infty} T^{\text {wait }}(i+1) P_{i}
$$

where $W T$ is the average waiting time in seconds for each passenger at each stop, $i$ is the extra vehicle numbers to be waited and $P_{i}$ is the probability of having to wait more than $i$ numbers of the public transport vehicle.

If we consider the previous single-decker bus example, the passenger waiting time calculated by using the equation in the spreadsheet model is:

$$
T^{\text {wait }}=\frac{65.45}{2}+23.64=56.36 s
$$

Therefore the average passenger waiting time if we use the queuing theory will be: 


$$
\begin{gathered}
W T=T^{\text {wait }}(0.63+2 \times 0.19+3 \times 0.09+4 \times 0.04+5 \times 0.02+6 \times 0.01) \\
=>W T=92.36 \mathrm{~s}
\end{gathered}
$$

The calculation only took the first 6 terms because the probability of having to wait for at least the $7^{\text {th }}$ incoming bus is smaller than $1 \%$ which would have a trivial effect on the total waiting time (e.g. the extra time to wait for the $7^{\text {th }}$ incoming bus is $1.97 \mathrm{~s}$ per passenger). This means for the passenger demand level of 60,000 per day on the $12 \mathrm{~km}$ corridor, each passenger may have to spend approximately half a minute more because of the queue length. This extra wait time will increase with the level of demand because the remaining capacity of the system is getting lower.

The application of queuing theory on the calculation of passenger waiting time takes the situation that the incoming vehicle has not enough space for all passengers into account. Another method to calculate this extra user cost for high levels of passenger demand has been demonstrated in Tirachini et al. (2010) which considered the passengers' willingness to pay by using the crowding penalty factor to account for the extra passengers' in-vehicle time costs. Both methods considered the effect that the demand level is higher than the supply, however, passengers may not only be unable to find a seat but also unable to get on the first incoming bus due to the large queue, and this situation is very likely to happen in a high population cities in peak period.

\section{Demand Supply Relationship}

To investigate the results after applying the revised speed-flow and waiting time equations, the final cost results of the single-decker bus in mixed traffic with both endogenous demand and exogenous demand are compared in this section. In the spreadsheet model, daily passenger demand level is changed in the calculation procedure for every 1,000 passengers, which means the demand is assumed to be 
exogenous - externally fixed by the spreadsheet model. This is because the supply requirement calculation model has to assume the level of passenger demand as externally fixed in the first place to obtain the total costs. However, it cannot reflect the situation that passengers' willingness to use the service varies according to the quality of service. As a result of that, a further analysis of demand and supply relationship must be conducted to obtain the actual average costs. The endogenous passenger demand in reality is closely related to the performances such as the service frequency, passenger waiting time and in-vehicle time for the whole journey.

In order to investigate the internal impact of the users' waiting time and invehicle time on the current demand level, the demand elasticity concept is introduced. The elasticity of demand can be defined as:

$$
E_{x}=\frac{\text { The proportional change in demand }}{\text { The proportional change in the variable of interest }}=\frac{\Delta Q / Q}{\Delta x / x} \quad \text { Equation } 16
$$

where $Q$ is the demand, $\Delta Q$ is the change in the demand, and $\Delta x$ is the change in the variable $x$ which we are interested in (e.g. service headway). In this definition, the variable $x$ can be any factor that would affect the demand level.

Time is one of the most important factors that impacts on the service quality of public transport, especially journey time and waiting time. Based on the elasticity definition, the endogenous passenger demand level can be calculated as:

$$
Q_{1}=Q_{0}\left(\frac{T_{1}^{\text {wait }}}{T_{0}^{\text {wait }}}\right)^{E_{1}}\left(\frac{J T_{1}}{J T_{0}}\right)^{E_{2}}
$$

where $Q_{1}$ is the endogenous passenger demand per day, $Q_{0}$ is the input exogenous demand level from 1,000 to 200,000 per day, $T_{1}^{\text {wait }}$ is the passenger waiting time in seconds at exogenous demand level of the public transport mode, $T_{0}^{\text {wait }}$ is the average passenger waiting time in seconds at a fixed demand level for all modes $(=10,000$ 
passenger trips per day), $J T_{1}$ is the journey time in seconds at exogenous demand level of the public transport mode, $J T_{0}$ is the average journey time in seconds at a fixed demand level for all modes ( $=10,000$ passenger trips per day), $E_{1}$ is the elasticity of demand with respect to waiting time, $E_{2}$ is the elasticity of demand with respect to journey time.

The demand elasticity of passenger waiting time was estimated by Preston and James (2000) based on an analysis with bus data in 23 urban areas in the Great Britain. These waiting time elasticities for UK cities analysis are reported by Balcombe et al. (2004), and the average elasticity is calculated as -0.64 . This elasticity value of -0.64 means every $1 \%$ of increasing or decreasing wait time will have an effect of a $0.64 \%$ decrease or increase in the demand level. For the elasticity of the passenger in-vehicle time, less journey time is always preferred. So for any increse in the time spent on board, passenger demand level will fall, which means the journey time elasticity is always negative. Review studies have been done all around the world for different cities. The in-vehicle time elasticity for buses is estimated to be approximately -0.4 by Daugherty et al. (1999) after reviewing bus priority schemes in Great Britain. So in the spreadsheet model, the waiting time elasticity for buses would then use -0.64 and an elasticity value of -0.4 would be adopted for bus journey time.

This equation uses elasticities of waiting time and journey time to calculate the difference between the fixed demand level and the endogenous demand level when the public transport services are operating. By applying this equation to the spreadsheet model for every step of the exogenous demand from 1,000 to 200,000, the original average demand level would change due to the elasticity factor, and then the graph of the endogenous demand against the original exogenous demand can be produced. To compare the difference of applying the endogenous demand, Figure 4Figure 4 is plotted 
according to the spreadsheet cost model results of the single-decker bus in mixed traffic (before applying the revised speed-flow and waiting time equations).
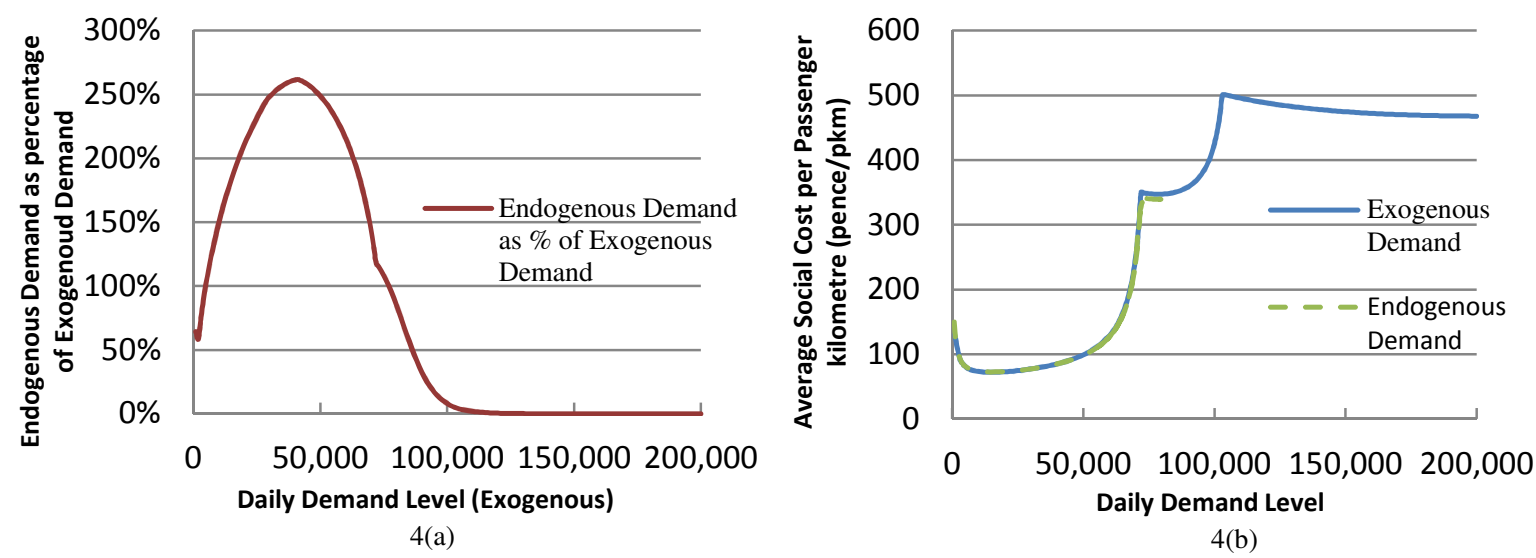

Figure 4 Average social cost of the single-decker bus in mixed traffic with exogenous demand and endogenous demand

In Figure 4 (a), the endogenous demand levels as a percentage of the exogenous demand $\left(Q_{1} / Q_{0}\right)$ are calculated by using Equation 17 and shown in the graph. This curve represents the impact of the quality of service to the attractiveness of the public transport service. For example, when the provided journey time and waiting time of the single-decker bus in mixed traffic are low (from demand level of 9,000 to 69,000 passengers per day), additional passengers are willing to use the service (by more than $50 \%$ of the exogenous demand, peaking at $150 \%$ ); when the demand is higher than 77,000 per day ( $100 \%$ of exogenous demand), the deterioration in service will bring the demand level down.

In Figure 4 (b), there are two inflection points at the demand level of 72,000 and 103,000. The safety headway capacity for peak period and off-peak period are reached at the demand level of 72,000 and 103,000 , respectively. This is because the public transport services reach the safety headway capacity and the service frequency cannot be increased, and therefore the average costs for the vehicle are reduced. After applying the endogenous demand, the social cost curve stops at the daily demand level of 76,700 , 
shown as the dotted line overlapped with the exogenous demand curve. This result means passengers are willing to use the public transport service until the maximum level (100\% of exogenous demand as shown in Figure 4 (a)) has been reached, and then any increase in demand will lead to a service which will bring the level of demand back to the maximum level based on the calculation of the elasticity analysis. As a result of that, with the limited quality of service for the single-deck bus in mixed traffic, the actual level of demand cannot accumulate up to 200,000 passengers per day.

For some public transport technologies, the total operator costs will be much lower than the exclusive facility technologies with higher infrastructure costs while the total user costs are very high due to the congestion time costs. By considering the impacts of journey time and waiting time cost to passengers, the advantages of these high infrastructure costs can be demonstrated in the spreadsheet cost model.

With the application of endogenous demand, the effects of the revised speedflow and waiting time equations on the total social costs can be assessed. Figure 5Figure 5 shows the average social costs of the single-decker bus in mixed traffic and the singledecker bus on a busway with endogenous demand from the spreadsheet cost model. 


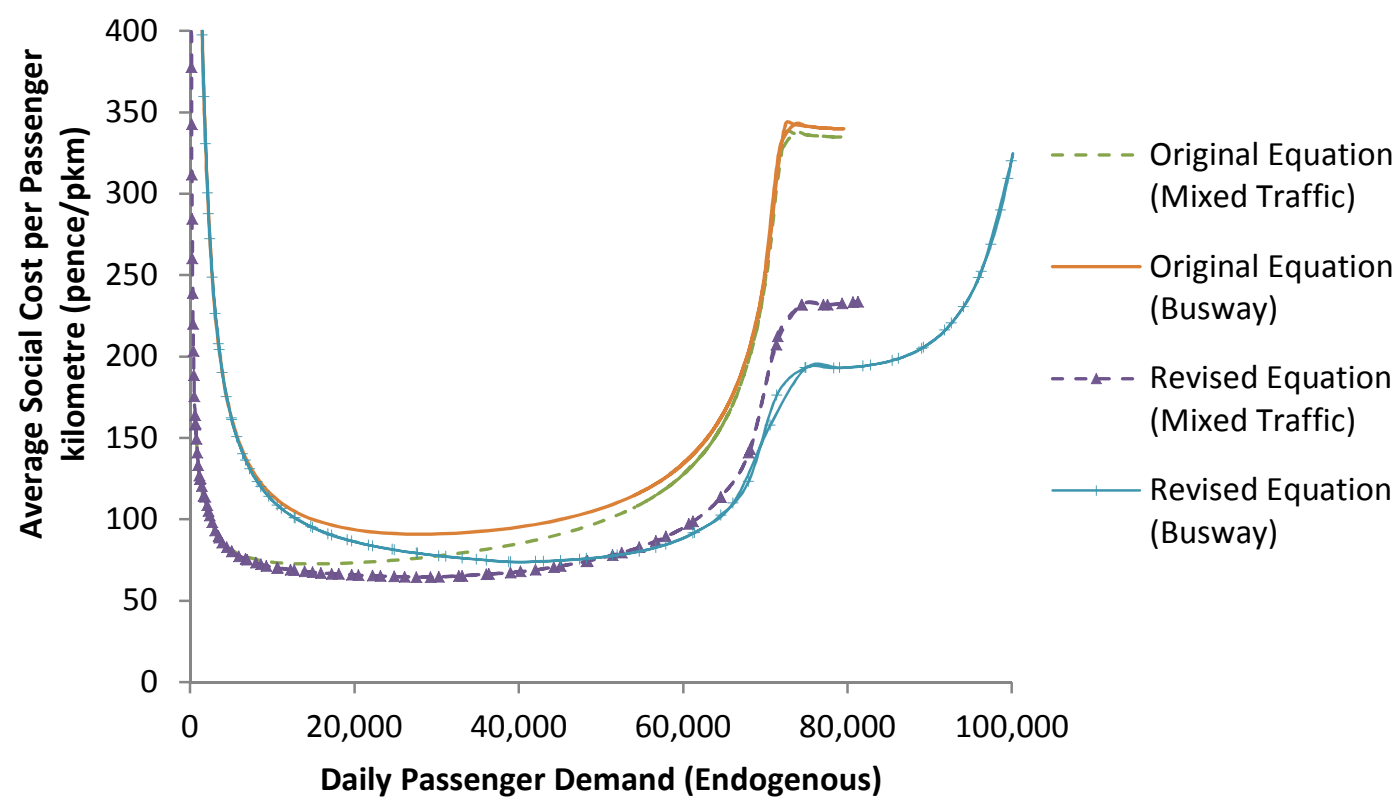

Figure 5 Average social cost of the single-decker bus in mixed traffic and on busway

The $\mathrm{x}$-axis in the graph indicates the demand level when it is influenced by the supplied public transport services. The average social costs calculated by using the original equations for different bus operating environments are shown in the graphs as the two top curves. Before they reach the safety headway capacity, the cost for the bus service in mixed traffic is lower because of the higher infrastructure costs of a busway. Without considering the advantage of having an exclusive transit lane in the original equations, the average social cost of the single-deck bus on a busway is always higher than the cost in mixed traffic at all demand levels.

The bottom two lines indicate the average social costs calculated by using the revised speed-flow and waiting time equations. At low demand levels, the single-decker bus in mixed traffic still stands out because of its lower infrastructure costs while their speed differences are not obvious. When the demand level reaches 51,400 per day for the $12 \mathrm{~km}$ corridor, the advantages of having exclusive transit facilities make the singledecker bus in a busway have the lowest average social costs. This is because high passenger demand levels would cause traffic congestion which lowers the operating 
speed, especially for the services in mixed traffic, and eventually makes the in-vehicle time higher. Passengers' waiting time would also be affected as the vehicles have to spend more time at stations/stops for those boarding/alighting passengers. The result of this demand and supply relationship analysis shows how the actual public transport performance would affect the passenger demand in reality as well as the results of applying the revised speed-flow and waiting time equations. Although the amendments have led to broadly similar shaped average social cost curves, they have led to changes in the cost minimising choice of technology.

\section{Conclusions and Future Work}

This paper reassessed the spreadsheet cost model developed in the TEST project and improved the model by adding the probability of having to wait longer than the expected service headways to the passenger wait time calculation and by considering the advantages in speed for the public transport services in different operating environment. Parameter values in the model are able to be modified according to any update of resources to fit the characteristics of the selected public transport technology.

The speed-flow equation takes the advantages of different operating environments into account after applying the piecewise linear function of average travel time. The speed of different forms of public transport can now represent the situation when they operate in different environments (mixed traffic, semi-exclusive, exclusive or grade-separated). According to the piecewise linear function, operating speed will start to decrease when the demand level reaches the facility capacity which is defined by the operating environment factor and the safety headways. For the public transport forms

with dedicated facilities, this factor would be higher and thus their operating speeds are higher at the same level of demand compared to the ones in mixed traffic environment. Passengers have to spend extra time in waiting because the capacity of public transport 
vehicles is fixed and the probability of being full for the incoming vehicle is getting higher at high demand levels. This has been calculated by using the queuing theory for the probability of having to wait longer than the expected service headways. As an illustration of the queuing theory application, the waiting time calculated by the spreadsheet model was 56.36s per passenger in peak periods for single-decker bus passengers at the demand level of 60,000 per day, and becomes 92.36s if we consider the probability of having to wait longer than the expected service intervals. An investigation of the effects of endogenous passenger demand has been presented to evaluate the revised equations. Exogenous demand is replaced by endogenous demand in order to highlight the advantages of different operating environments. The infrastructure costs are relatively fixed for a public transport technology, the vehicle number required is associated with vehicle capacity and therefore the waiting time and the in-vehicle time would change for different demand levels. According to the comparison result graph, the revised equations demonstrated a lower average user cost for the forms of public transport with exclusive transit facilities.

As a strategy level model, the spreadsheet model can be used by decision makers to assess the financial and social costs of existing public transport services on the corridor as well as conceptually new technologies such as straddle bus. The financial and social costs of different public transport technologies on a selected corridor are compared to find out the lowest costs public transport forms for operators, users or both. Due to the size, location and other situations of different public transport corridors in different cities, the demand level would vary. The spreadsheet model can help to assess the choice of choosing the most suitable public transport technology in different cities. Further work for this model would be focused on improving it by microsimulating the operations of these public transport modes in a selected urban area 
using the transportation analysis software VISSIM. Microscopic simulation would be adopted in order to observe the characteristics of the individual vehicles for different public transport technologies in an urban network in order to consider the performance in mixed traffic flow. This would have advantages over macro-level traffic models, such as VISUM, as it would permit detailed modelling of key capacity pinch points, namely stops and junctions. The urban area for simulation has been identified to be the main corridor in Nanning, China, where the passenger demand level is about 90,000 100,000 per day. The current government decision is to build an underground heavy rail system to meet this high passenger demand. However, preliminary analysis in the spreadsheet model suggests that other public transport technologies, such as the straddle bus, could also be a competitive choice in that demand range, as shown in Figure

\section{Figure 6.}

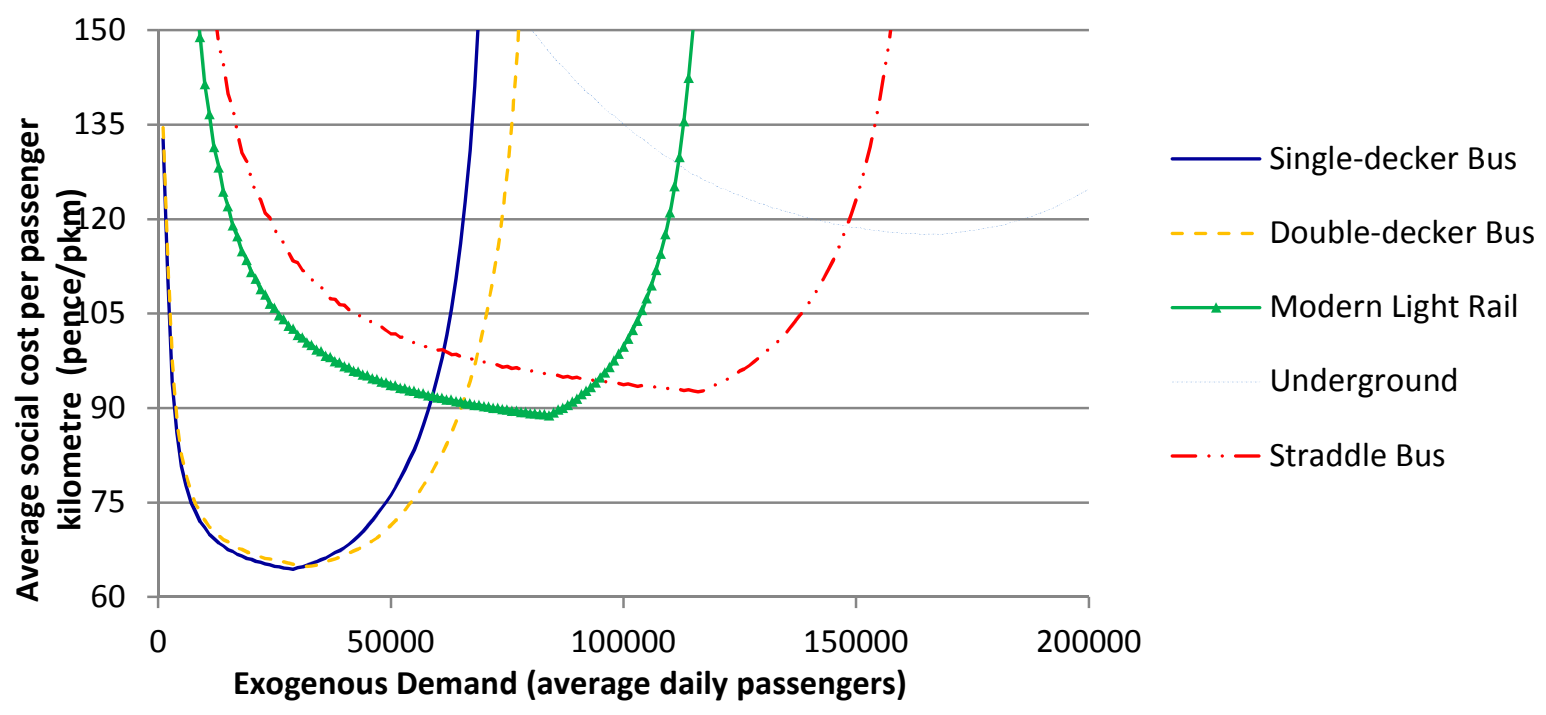

Figure 6 Preliminary output of the spreadsheet model

The graph shows that the straddle bus may be a suitable intermediate public transport technology between conventional bus and underground, with a lowest average social cost between demand range of 92,000 and 148,000 per day on the assumed corridor in the spreadsheet model. This preliminary result from the spreadsheet model is 
also based on exogenous demand, and the effect of applying endogenous demand may also change the result. Therefore, a further complete demand and supply analysis is going to be performed for all different public transport technologies in the spreadsheet model and a complete traffic network would be built in the future work to analyse the costs for all road users and compared between different public transport technologies.

\section{References}

Balcombe, R., Mackett, R., Paulley, N., Preston, J., Shires, J., Titheridge, H., Wardman, M. and White, P. 2004. The Demand for Public Transport: A Practical Guide. Transport Research Laboratory Report TRL 593, Crowthorne, UK.

Brand, C. and Preston, J. 2001. Technical and Financial Characteristics of Public Transport Systems. TSU Working Paper (Ref. 911), Transport Studies Unit, University of Oxford.

Brand, C. and Preston, J. 2002a. The Field Studies - Synthesis of Results. TSU Working Paper (Ref. 931), Transport Studies Unit, University of Oxford.

Brand, C. and Preston, J. 2002b. The Wider Costs and Benefits of Urban Public Transport Systems. TSU Working Paper (Ref. 919), Transport Studies Unit, University of Oxford.

Brand, C. and Preston, J. 2003a. The Software Tool : Specification and Case Study Validation. TSU Working Paper (Ref. 948), Transport Studies Unit, University of Oxford.

Brand, C. and Preston, J. 2003b. "Which technology for public transport? - A review of system performance, costs and impacts." Proceedings of the Institution of Civil Engineers - Transport, 156. TR4, pp.201-210. 
Brand, C. and Preston, J. 2006. "TEST - A tool for evaluating strategically integrated public transport." Paper presented at European Transport Conference, Strasbourg, France, 18 - 20 Sep 2006.

Currie, G. 2006. "BRT in Australasia: Performance, Lessons Learned and Futures." Journal of Public Transportation, Volume 9, No. 3, 2006 Special Edition: Bus Rapid Transit.

Currie, G. and Wallis, I. 2008. "Effective ways to grow urban bus markets-a synthesis of evidence." Journal of Transport Geography. 16, 419-429.

Daugherty, G, G., Balcombe, R, J. and Astrop, A, J. 1999. A comparative assessment of major bus priority schemes in Great Britain. TRL Report TRL409, Crowthorne, UK.

Department for Transport. 2012. Transport Statistics Great Britain 2012. Available from: https://www.gov.uk/government/publications/transport-statistics-greatbritain-2012 [Accessed 26 June 2013]

Glaister, S. 1981. Fundamentals of Transport Economics. Blackwell, Oxford.

Jakob, A., Craig, J.L. and Fisher, G. 2006. "Transport cost analysis: a case study of the total costs of private and public transport in Auckland." Environmental Science \& Policy 9 (1): 55-66. DOI: 10.1016/j.envsci.2005.09.001.

Jansson, J. O. 1984. Transport System Optimisation and Pricing. Wiley, Chichester.

Kittelson \& Associates, Inc., et al. 2013. Transit Capacity and Quality of Service Manual 3rd Edition. Transportation Research Board.

Knowles, R. D. 2007. "What future for light rail in the UK after Ten Year Transport Plan targets are scrapped?" Transport Policy 14: 81-93. DOI: 10.1016/j.tranpol.2006.10.001. 
Li, X. and Preston, J. 2014 Forthcoming. "Reassessing the financial and social costs of public transport." Proceedings of the Institution of Civil Engineers - Transport.

McDermon, D. 2010. "Riding High: A Chinese Concept for Bus Transit.” New York Times, 08 August 2010. http://wheels.blogs.nytimes.com/2010/08/05/ridinghigh-a-chinese-concept-for-bus-transit/ [Accessed 01 March 2012].

Meyer, J. R., Kain, J. F. and Wohl, M. 1965. The Urban Transportation Problem. Harvard University Press.

Preston, J. and James, T. 2000. Analysis of demand for bus services. Final report. Transport Studies Unit, University of Oxford.

Tirachini, A., Hensher, D. A., and Jara-Díaz, S. R. 2010. "Comparing operator and users costs of light rail, heavy rail and bus rapid transit over a radial public transport network." Research in Transportation Economics 29 (1): 231-242. DOI: $10.1016 /$ j.retrec.2010.07.029.

Small, K. A. 1992. Urban transportation economics. Chur, Switzerland.

ULTraGlobalPRT. 2011. "ULTra at London Heathrow Airport.” ULTraGlobalPRT. Accessed 28 March 2012. http://www.ultraglobalprt.com/heathrow/. 